\title{
Errors and misquotations in the study of shisha, blood pressure and heart rate in Jordan
}

\author{
Kamal Chaouachi
}

Received: 2 December 2008 / Accepted: 19 January 2009/Published online: 21 February 2009

(C) Springer-Verlag 2009

\begin{abstract}
Aim This comment is based on a critical review of a study on blood pressure and heart rate in shisha (narghile, hookah) smokers in Jordan.

Subjects and methods The study was analysed against the most recent literature on this issue, in general, and against peer-reviewed biomedical publications from the Middle East, in particular.

Results Several errors and misquotations were found in the study under scrutiny. Most of them stem from misrepresentations related to the chemistry of shisha smoke, the anthropology and geography of its use, and the relevance of the literature cited by the authors (vs. the non-cited one), both from a quality and quantity viewpoint.

Conclusion A clarification is made about all these points of utmost importance and will hopefully help a new generation of researchers avoid wading too far in this field. Against the background of a world epidemic, public health interventions will gain credibility and performance.
\end{abstract}

Keywords Smoking · Shisha - Narghile · Tobacco ·

Heart rate $\cdot$ Blood pressure

In their introduction, Al-Safi et al. wrongly credit Kiter for mentioning countries such as China, India or Pakistan (AlSafi et al. 2008; Kiter et al. 2000). Then, they endorse the idea that "maassel" "simplifies water pipe preparation", whereas this smoking product has actually made shisha

\footnotetext{
K. Chaouachi $(\bowtie)$

Tobacco Researcher and Consultant, DIU Tabacologie,

Paris XI University,

18 , allée des petits bois,

78000 Versailles, France

e-mail: kamcha@gmail.com
}

smoking more complex than the ones traditionally used for centuries, mainly tumbak ("'ajamy") and jurak. Indeed, besides the well-known and "ritual" complicated procedures described in all anthropological studies, a tin (aluminium) foil has to be carefully prepared by piercing it and placing it over the bowl of the pipe. This innovative tool actually serves as a thermal screen between the smoking mixture and the charcoal, whereby the former is only heated by the latter and not burnt as in cigarettes. This has extremely important consequences for the chemical reactions involved (distillation vs. pyrolysis), which completely differ from those occurring in the tobacco rod of a cigarette (Chaouachi 2007).

According to the authors, "water pipe" smoking is associated with an increased risk of lung cancer. This statement is in contradiction with the results of comprehensive and critical reviews of the related literature over several decades, as described in a recent study (Sajid et al 2008). Al-Safi et al. cite a publication that shows "a high increase in heart rate and blood pressure and markedly impaired baroreflux sensitivity" (Al-Kubati et al. 2006). However, there was an important unnoticed bias in this study, because only $5 \mathrm{~g}$ of the smoking product (moassel) was used for a whole 45-min session, whereas the common amount used in most reliable studies of the Middle East, and particularly Jordan, is $20 \mathrm{~g}$ (Bacha et al. 2007; Shafagoj and Mohammed 2002; Hadidi and Mohammed 2004). Under such unusual conditions, the smoking mixture may char rapidly with a consequent overproduction of $\mathrm{CO}$, carbonaceous material and tar. Interestingly, shisha smoke contains high proportions of water and glycerol. Its tar differs totally from cigarette tar. On the whole, shisha smoke is much less complex than cigarette smoke, as was established early on by El-Aasar and El-Merzabani (1991). These researchers identified only 142 compounds in the 
former, to which others, related to the presence of charcoal, should be added, however. By comparison, cigarette smoke contains about 4,700 chemical compounds.

Al-Safi et al. state that there is a "significant elevation of the mean SBP, DBP, ABP, and heart rate values in shisha smokers compared to non-smokers". This is above all true for mixed cigarette/shisha smokers. The third column of Table 4 is striking in this respect. The increase of arterial blood pressure in "pure"/exclusive shisha smokers from $92.57 \pm 13.90$ to $92.62 \pm 10.58$ (NS) (Table 4) may be "significant" in statistical terms, but remains quite modest, as does the increase in heart rate from $76.40 \pm 10.46$ to $76.81 \pm 10.19$ (NS). This is certainly in agreement with Shafagoj and Mohammed (2002), who, in their study, found only a light increase of the above parameters.

Finally, it is surprising to see that the publications of the US-Syrian Centre for Tobacco Studies are cited 80 times in a manuscript of only six pages. Furthermore, 64 of these citations concern one chief author, Maziak, who is the director of that centre. In the first two paragraphs, Maziak is cited 18 times, perhaps even 22 times since it appears that "Asfar et al. 2004a, b, c, d" (line 9) apparently refers to the same author.

Competing interests I have no competing interests. I have never received direct or indirect funding either from pharmaceutical companies (nicotine "replacement" therapies and products) or from the tobacco industry.

\section{References}

Al-Kubati M, Al-Kubati AS, Al'absi M, Fiser B (2006) The short term effect of water-pipe smoking on the baroreflex control of heart rate in normotensives. Auton Neurosci 126:146-149

Al-Safi SA, Ayoub NM, Albalas MA, Al-Doghim I, Aboul-Enein FH (2008) Does shisha smoking affect blood pressure and heart rate? J Public Health [Online First, 15 Nov 2008]

Bacha ZA, Salameh P, Waked M (2007) Saliva cotinine and exhaled carbon monoxide levels in natural environment waterpipe smokers. Inhal Toxicol 19(9):771-777

Chaouachi K (2007) The medical consequences of narghile (hookah, shisha) use in the world. Rev. épidémiol Santé Publique (Epidemiology and Public Health) 55(3):165-170

El-Aasar AM, El-Merzabani MM (1991) Studies on jurak smoke. I. The organic constitutents of jurak smoke. Journal of King Abdulaziz University (Science) 3:169-181

Hadidi KA, Mohammed FI (2004) Nicotine content in tobacco used in hubble-bubble smoking. Saudi Med J 25(7):912-917

Kiter G, Ucan ES, Ceylan E, Kilinc O (2000) Water-pipe smoking and pulmonary functions. Respir Med 94:891-894

Sajid KM, Chaouachi K, Mahmood R (2008) Hookah smoking and cancer. Carcinoembryonic antigen (CEA) levels in exclusive/ever hookah smokers. Harm Reduction Journal 24 May;5(19) http:// www.harmreductionjournal.com/content/5/1/19

Shafagoj YA, Mohammed FI (2002) Levels of maximum end expiratory carbon monoxide and certain cardiovascular parameters following hubble-bubble smoking. Saudi Med J 23:953-958 